\title{
Negative Impacts of the Adaptation Process Linked to Local Cultural Stress Levels in Immigrants and Development of Psychiatric Disorders: A Systematic Review and Meta-Analysis
}

Mayana Rodrigues de Melo Alves ${ }^{1}$, Jéssica Luma Maques Freitas ${ }^{1}$, Modesto Leite Rolim Neto1,2

\section{Abstract}

Background: Current studies underline and enable the international scientific community to reflect on migrant needs to restart, mostly without fluency in the language from the country of destination, without a way of proving his/her knowledges and abilities, with an incomplete family core, without cultural references that until that moment defined him/her as belonging to a specific group, with defined and meaningful habits, full of symbolic representations.

lams: Conduct an analysis on the implications of migration in refugees' mental health, and the link between these implications and Post-traumatic Stress Disorder (PTSD).

Method: Indexed journals in MEDLINE and LILACS databases hosted in Biblioteca Virtual em Saúde (BVS), as well as papers hosted in Coordenação de Aperfeiçoamento de Pessoal de Nível Superior (CAPES) Periodicals Portal. Searches were carried using the following DeCS descriptors: "Stress Disorders, Post-Traumatic", "Refugees" e "Mental Health".

Results: The 10 studies included in the present review were carried in Australia, Denmark, Ethiopia, Turkey, Uganda, Israel, South Korea and Papua New Guinea, and were published in 2014 (2), 2015 (6), and 2017 (2). Regarding the subject, 50\% of the articles concentrate information regarding PTSD and mental health problems, while the
1 Faculty of Medicine, Estácio/FMJ, Juazeiro do Norte, Ceará, Brazil.

2 Universidade Federal do Cariri, UFCA, Faculdade de Medicina, Barbalha, Ceará, Brazi.

Contact information:

Modesto Leite Rolim Neto.

Address: Universidade federal do Cariri, UFCA. Faculdade de Medicina. Barbalha, Ceara, Brazil.

”modestorolim@yahoo.com.br 
remaining half deals with psychosocial effects of mass conflict on refugees. Meta-analysis concludes that a considerable percentage of refugees suffer from psychiatric disorder, I-squared (variation in ES attributable to heterogeneity) $=96.46 \%$; Estimate of between-study variance $\operatorname{Tau}^{\wedge} \mathrm{Z}=0.02$. Test of $E S=0: z=17.75 p=0.00$.

Conclusion: Exposure to traumatic events such as public executions and other extreme acts of violence, murder of family members, family and friends' death due to starvation, homelessness, are closely related to PTSD prevalence in refugees. Acculturation and family's prolonged estrangement are predictors of depressive symptoms in refugees and both exposure to a new culture and adaptation to new laws and norms of welcoming countries act as stressors and aggravators of depressive symptoms.

\section{Keywords}

Post-traumatic Stress

Disorders; Refugees; Mental

health; War disturbs; Violence.

\section{Introduction}

Migrations have been frequent worldwide since ancient times. However, migration volume has varied depending on the historical period, as well as their motivations [1]. Europe has been experiencing the largest movement of people since World War II. In 2015, more than 1.2 million people required asylum from European Union, mostly from Syria, Afghanistan and Iraq. Many of them have endured war, shock, agitation, and hideous trips [2]. In first semester of 2017, the United Nations High Commissioner for Refugees (UNHCR) recorded a drop in number of refugees and migrants arriving in Europe, mainly due to decline of $94 \%$ in number of people using the Turkish sea route to Greece. However, a high probability of death among those seeking to reach this continent is still highlighted [3].

Refugee is defined as a person who, as a result of fear from persecution caused by several factors, crosses their country of origin national borders in search of protection, not being able to return to their place of origin fearing a threaten to his/her integrity $[4,5]$. For these people, refusal of asylum may have vital consequences, for they will need asylum somewhere else [6]. Thus, they aim to become internationally recognized 'refugees', in order to have access to assistance from States, UNHCR and other organizations.

Considering that international refugee law cannot be conceived outside the landmark of International Human Rights, the principle of 'non-refoulement' is the cornerstone of international refuggee protection, a principle closely related to the warrancy of several civil, political, economic, social and cultural right [7].

Refuge is ambivalent 'par excellence', as it allows survival while triggers an irreversible rupture with the abandoned homeland. These unplanned - and sometimes unwanted - departures are often associated with psychological distress, directly related to the trauma to which refugees were submitted in pre-migratory and migratory times $[8,9]$. That is when, taking the complex history of migration into account, concerns for these people's health began to emerge. It is known that timely access to adequate health care is essential for physical and mental well-being [10]. 
Pre-migration experiences, such as physical and psychological violence in the country of origin, loss of home and loved ones, stress of forced migration and post-migration trials can cause or amplify intense psychological distress in refugees and increase their chances of developing Post-traumatic Stress Disorder (PTSD) [11]. PTSD prevalence rates among refugees are high compared to general population, ranging from 5 to $31 \%$. PTSD strongly interferes with refugees' ability to act and recognize themselves as individuals: in their families, communities and society as a whole [12].

This study aims at analyzing the implications of migration process and the search for asylum in mental health among refugees' populations worldwide. Research starts from a guiding question based on the acronym PICo ( $\mathrm{P}$, population; I, interest; and $\mathrm{Co}$, context): what is the impact of migration process on mental health and on PTSD genesis in refugee populations?

A migrant is the subject located outside the cultural geographic zone in which he/she was raised. The migrant needs to restart, mostly without fluency in the language from the country of destination, without a way of proving his/her knowledges and abilities, with an incomplete family core, without cultural references that until that moment defined him/her as belonging to a specific group, with defined and meaningful habits, full of symbolic representations. [8] Thus, the hypothesis is that despite advances and agreements aiming to protect this group signed between 1951 and the present day, negative impacts of the adaptation process linked to local cultural differences cause high stress levels in immigrants and provide fertile ground for development of psychiatric disorders.

\section{Methods}

A systematic review with meta-analysis was carried through search of original articles in electronic databases. Searches were carried using Biblioteca Vir- tual em Saúde (BVS), that hosts MEDLINE and LILACS electronic databases at http://bvsalud.org/, as well as using Periodicals Portal of da Coordenação de Aperfeiçoamento de Pessoal de Nível Superior (CAPES), a virtual library created by Brazilian Ministry of Health, with restricted content, available for authorized users only, and that hosts national and international articles at http://www.periodicos.capes.gov.brl. Articles ranging from 2012 and 2017 were selected during August 2017, despite acknowledging the fact that migrations exist since ancient times. However, in view of recent conflicts and uproar over the disclosure of Syrian boy Aylan Kurdi's photo, who was found dead drowned on a beach in Turkey and became a symbol of Middle East and Africa migratory crisis in 2015, more recent research has been used [13]. Taking into account attention given by media to the case, this study tried to verify if this commotion was accompanied by scientific research interest and, more specifically, if studies sought to investigate PTSD in this population.

The following descriptors were used, in Portuguese, for searching on BVS and CAPES databases:

\# 1. "Stress Disorders, Post-Traumatic" (Health Science Descriptors [DeCS]);

\# 2. "Refugees" (DeCS);

\# 3. "Mental Health" (DeCS).

Search was carried using Boolean operators, as follows: "1 AND 2 AND 3" [BVS] and "1 AND 2" [CAPES].

Manuscripts' selection occurred primarily through analysis of titles and abstracts. The analysis followed eligibility criteria previously determined by inclusion criteria: (1) publications written in English, Spanish or Portuguese; (2) articles that have in their title at least a combination of the terms described in the search strategy; (3) articles addressing migratory process impacts on mental health of immigrants (refugees); (4) original studies with integral text accessible through Periodicals Portal of CAPES and BVS. 
The following articles were excluded: (1) non-original studies, such as letters to Editor, prefaces, brief communications, corrections/errata, comments, editorials, reviews, monographs, dissertations and theses. (2) Articles with a source of study data prior to 2012. Manuscripts repeated in more than one databases were counted only once. To ensure greater reliability of findings, the data collection was done by four researchers individually, and the divergences resolved by a third senior researcher.

Each article was fully read and the information was entered into a spreadsheet included Author and Year, Sample Study and Main Findings (PICO) (Table 1). This present study is a Literature Review; therefore, it did not involve patient recruitment. In this sense, approval of the Research Ethics Commit-

Table 1. Articles included in the study, according to Author, Publication Year, Journal and Main findings.

\begin{tabular}{|c|c|c|c|c|}
\hline Authors & Year & Journal & Sample & Main findings \\
\hline $\begin{array}{l}\text { Slewa- } \\
\text { Younan, S. }\end{array}$ & 2017 & $\begin{array}{l}\text { International } \\
\text { Journal of } \\
\text { Mental Health } \\
\text { Systems }\end{array}$ & $\begin{array}{l}\text { Interviews were conducted with } \\
225 \text { Iraqi and } 150 \text { Afghans. } \\
\text { Interviews were carried } \\
\text { between April, } 2013 \text { and } \\
\text { October, 2013; each session } \\
\text { lasted for up to } 90 \text { min. }\end{array}$ & $\begin{array}{l}\text { Compared to Iraqi group, Afghan group was } \\
\text { significantly younger, had lower schooling, had } \\
\text { longer period of displacement and was in Australia } \\
\text { longer. Afghans were relatively more likely to } \\
\text { believe that "family problems" and "moving to } \\
\text { a new country" caused PTSD in detriment of } \\
\text { "destiny" compared to Iraqi. }\end{array}$ \\
\hline $\begin{array}{l}\text { Nygaard, } \\
\text { M. }\end{array}$ & 2017 & $\begin{array}{l}\text { BMC } \\
\text { Psychiatry }\end{array}$ & $\begin{array}{l}\text { Inclusion criteria were an } \\
\text { initial psychiatric evaluation } \\
\text { at Competence Center for } \\
\text { Transcultural Psychiatry (CTP) } \\
\text { from June } 14,2011 \text { to March } \\
29,2012 \text { and with a diagnosis } \\
\text { of discharge from PTSD } \\
(n=220) \text {. }\end{array}$ & $\begin{array}{l}181 \text { patients were diagnosed with PTSD. Most } \\
\text { of the identified symptoms were auditory } \\
\text { hallucinations and persecutory delusions. The study } \\
\text { highlights difficulties that distinguish psychotic } \\
\text { features of flashback and draws attention to } \\
\text { psychotic features in patients with PTSD, in order } \\
\text { to improve documentation and understanding of } \\
\text { disorder. }\end{array}$ \\
\hline Feyera, F. & 2015 & $\begin{array}{l}\text { BMC } \\
\text { Psychiatry }\end{array}$ & $\begin{array}{l}847 \text { adult refugees were } \\
\text { interviewed in May, } 2014 \\
\text { at Melkadida camp in } \\
\text { southeastern Ethiopia. }\end{array}$ & $\begin{array}{l}\text { More than one-third (38.3\%) of the interviewed } \\
\text { met criteria for diagnostic symptoms for depression } \\
\text { Sex, marital status, previous displacement as a } \\
\text { refugee, murder of family or friends, homelessness } \\
\text { or shelter, and exposure to a large number of } \\
\text { cumulative traumatic events were significantly } \\
\text { associated with depression among the sample. }\end{array}$ \\
\hline
\end{tabular}

Hecker, T. 2015 Journal of Traumatic Stress

McGregor, 2015 The Journal L. S.
329 civilian refugees from Eastern Democratic Republic of Congo were interviewed between March and June, 2013 at Nakivale Refugee Settlement in Western Uganda. 58.3\% $(n=169)$ of these were women.

50 young people who identified themselves as refugees and lived in Hobart or Melbourne, Australia, participated in the study. Data were collected between April, 2012 and August, 2013.
Exposure to war-related trauma correlated positively with exposure to family and community violence. The relation between war-related trauma exposure and reactive aggressive behavior was mediated by PTSD symptoms and repetitive aggression. Findings were congruent with hypotheses' cycle of violence and indicate a differential relationship between distinct subtypes of aggression and PTSD.

Youngsters who were separated from immediate relatives showed significantly more PTSD symptoms than their counterparts, and there was a relationship between evasive coping and PTSD. Evidence for integrity of family unit was found as a correlation of PTSD in young refugees, but no evidence of a relationship between coping style and family separation was found. 


\begin{tabular}{|c|c|c|c|c|}
\hline Authors & Year & Journal & Sample & Main findings \\
\hline Nakash, O. & 2015 & $\begin{array}{l}\text { Cultural } \\
\text { Diversity and } \\
\text { Ethnic Minority } \\
\text { Psychology }\end{array}$ & $\begin{array}{l}118 \text { asylum seekers from } \\
\text { Eritreia and Sudan who } \\
\text { sought health services in } \\
\text { Israel between April, } 2012 \\
\text { and June, } 2013 \text {. Participants } \\
\text { included } 91 \text { Eritreans and } \\
27 \text { Sudaneses. Most of } \\
\text { participants were men. }\end{array}$ & $\begin{array}{l}\text { Acculturation leads to appearance of depressive } \\
\text { symptoms among asylum seekers. It highlights the } \\
\text { paradox of cultural assimilations and risks to mental } \\
\text { health among those who wish to be part of the new } \\
\text { culture. Exposure to traumatic events was significantly } \\
\text { associated with depression. Acculturation patterns } \\
\text { were associated with depression rates, even after } \\
\text { accounting for sociodemographic variables, detention } \\
\text { and exposure to trauma. }\end{array}$ \\
\hline Park, J. & 2015 & $\begin{array}{l}\text { Journal of } \\
\text { Psychosomatic } \\
\text { Research }\end{array}$ & $\begin{array}{l}213 \text { North Korea refugees } \\
\text { who settled in South Korea } \\
\text { between } 2000 \text { and } 2012 \\
\text { participated in the study. } \\
\text { Of the participants initially } \\
\text { recruited, } 14 \text { were unable to } \\
\text { complete the questionnaires } \\
\text { and their data were } \\
\text { excluded. Of the remaining } \\
199 \text { participants, } 147 \text { were } \\
\text { female. }\end{array}$ & $\begin{array}{l}\text { Most frequent psychological trauma were } \\
\text { witnessing public executions, witnessing deaths } \\
\text { of family members or friends of starving, starving, } \\
\text { witnessing severe physical violence and escaping } \\
\text { after desertion. Male participants experienced more } \\
\text { trauma compared to women. No significant gender } \\
\text { differences were found for results of psychiatric } \\
\text { questionnaire. Age was positively correlated with } \\
\text { the number of psychological traumas experienced. } \\
\text { As individuals experience traumatic events, clearly } \\
\text { identifying and expressing emotions become crucial } \\
\text { to reducing PTSD symptoms. }\end{array}$ \\
\hline Tay, A. K. & 2015 & $\begin{array}{l}\text { Social Science } \\
\text { \& Medicine }\end{array}$ & $\begin{array}{l}230 \text { adults from West Papua } \\
\text { with an average age of } 37 \\
\text { participated in the study. }\end{array}$ & $\begin{array}{l}\text { Symptoms that were most frequently cited by study } \\
\text { participants were intrusive thoughts, psychological } \\
\text { and physiological reactions, flashbacks, distressing } \\
\text { dreams. Other reported symptoms include insomnia, } \\
\text { post-traumatic amnesia, affective dysregulation, } \\
\text { decreased interest and hypervigilance. Men presented } \\
\text { higher levels of PTSD symptoms than women. It is } \\
\text { suggested that exposure to specific traumatic events } \\
\text { is mediated by psychosocial influence of appearance } \\
\text { of PTSD symptoms. }\end{array}$ \\
\hline $\begin{array}{l}\text { Slewa- } \\
\text { Younan, S. }\end{array}$ & 2014 & $\begin{array}{l}\text { BMC } \\
\text { Psychiatry }\end{array}$ & $\begin{array}{l}225 \text { participants were } \\
\text { interviewed during a } \\
10 \text {-month period. All } \\
\text { participants were resettled } \\
\text { Iraqi refugees who attend } \\
\text { the Adult Migrant English } \\
\text { Program (AMEP) at several } \\
\text { different colleges in Australia. }\end{array}$ & $\begin{array}{l}\text { Approximately one third ( } 31.1 \% \text { ) of participants } \\
\text { reached the threshold for clinically significant PTSD } \\
\text { symptomatology. } 84.9 \% \text { of respondents indicated } \\
\text { that seeing a psychiatrist would be helpful, followed } \\
\text { by reading the Quran, or the Bible, selected by } \\
79.2 \% \text { of respondents. There was some variation in } \\
\text { recognition of problem and utility of the treatment, } \\
\text { mainly influenced by resettlement period in Australia. }\end{array}$ \\
\hline Alpak, G. & 2014 & $\begin{array}{l}\text { Int J Psychiatry } \\
\text { Clin Pract }\end{array}$ & $\begin{array}{l}352 \text { people took part in the } \\
\text { study between November, } \\
\text { 1st and November, 20, } 2013 \\
\text { in Turkey, where a group } \\
\text { of Syrian refugees live. The } \\
\text { only inclusion and exclusion } \\
\text { criteria for the study was } \\
\text { volunteering. }\end{array}$ & $\begin{array}{l}\text { The frequency of PTSD was 33.5\%; chronic type } \\
\text { was } 89 \% \text {, whereas late onset type occurred in } \\
1.7 \% \text { and spontaneous remission in } 11.6 \% \text {. A } \\
\text { significant relationship was detected between } \\
\text { number of traumatic events and diagnosis of PTSD. } \\
\text { The probability of having PTSD in sample was } 71 \% \\
\text { when it had following characteristics: female gender; } \\
\text { diagnosis of previous psychiatric disorder; have a } \\
\text { family history of psychiatric disorder and have been } \\
\text { experiencing } 2 \text { or more traumas. }\end{array}$ \\
\hline
\end{tabular}

Source: Own authorship. 
tee is not necessary. This review was based on PRISMA protocol (http://www.prisma-statement.org/)

RevMan, a software that points towards key elements of a meta-analysis, i.e. proportion between studies, was used in the present review.

\section{Results}

Initially, research strategies using descriptors only resulted in 1,442 studies at BVS and 473 at Periodicals
Portal CAPES. When filters were applied, the search was narrowed to 361 studies. After reviewing titles and abstracts, 95 articles were retrieved, 10 of which were included for full text reading (Figure 1) in relation to the following aspects: main author, year of publication, periodical and main findings. Among the articles included in the review, none were in Portuguese and none have national origin; studies were carried in Australia [14, 15, 16], Denmark [17], Ethiopia [18], Turkey [19], Uganda [20],

Figure 1: Flow chart of eligibility process of articles from BVS (MEDLINE/LILACS) and CAPES databases.

\section{BVS (MEDLINE/LILACS)}

들 Stress Disorders, Post-Traumatic (DeCS) AND Refugees (DeCS) AND Mental Health (DeCS) Index: Title, abstract and subject.

Period: January, 2012 to August, 2017

\section{CAPES}

Stress Disorders, Post-Traumatic (DeCS) AND Refugees (DeCS) Index: Title, abstract and subject.

Period: January, 2012 to August, 2017

\section{1,442 results}

\section{3 results}

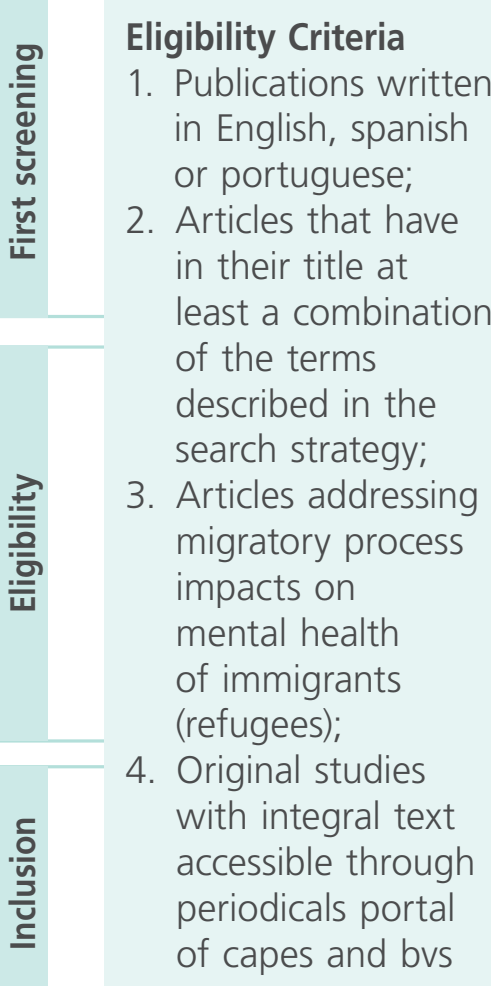

Studies selected after applying filters for title and abstract analysis. (BVS: $N=226$; Periodicals Portal of CAPES: $N=135$ ) Total: $\mathbf{n}=361$

\section{Excluded articles for not reaching inclusion criteria $(n=266)$}

Studies selected after title and abstract analysis.

(BVS: $N=31$; Periodicals Portal of CAPES: 36)

Total: $\mathbf{n}=95$ studies

\section{Excluded studies, according} exclusion criteria ( $n=85)$

1. Studies published prior to 2012 ( $n=46$ );

2. Repeated studies $(n=11)$;

3. Non-original studies $(n=28)$.

Studies included in the critical analysis $(n=10)$ 
Figure 2: Number of studies published at BVS database, according to publication year.

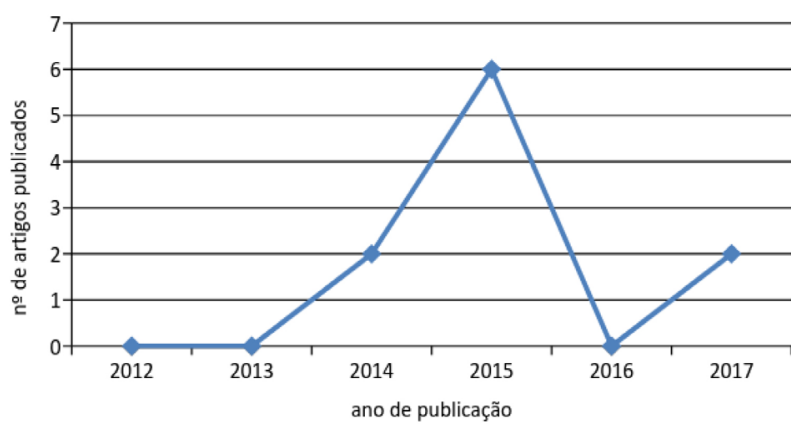

Source: Own authorship.

Figure 3: Proportions meta-analysis.

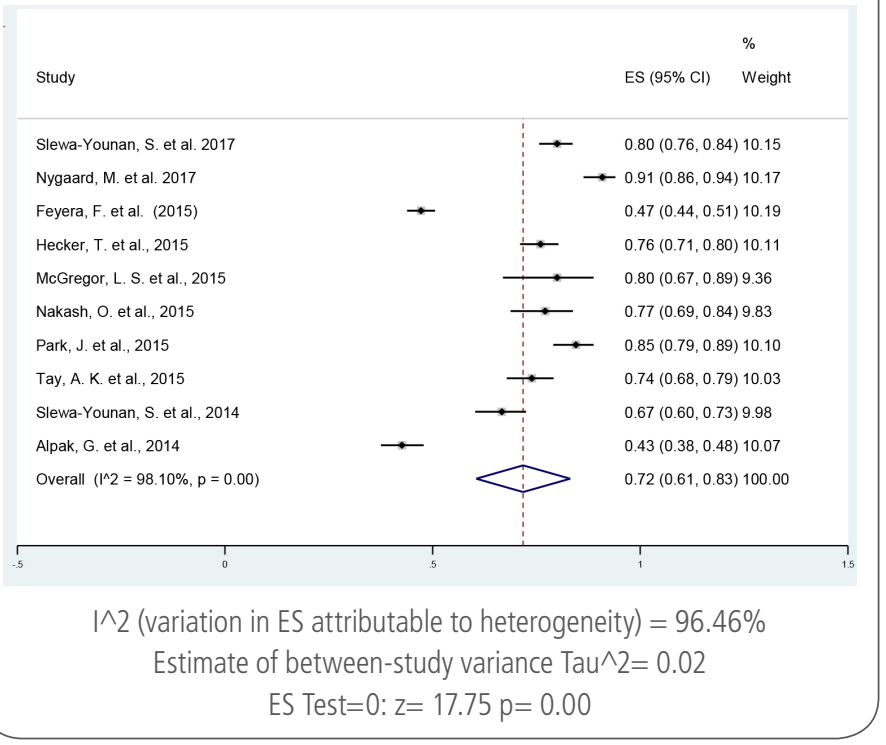

Israel [21], South Korea [22] and Papua New Guinea [23], published in 2014 (2) [16, 19], 2015 (6) [14, 19, 20, 21, 22, 23], and 2017 (2) [15, 17] (Figure 2). Analysis allows the conclusion that there is a significant proportion of phsychiatric disorder among refugees' population (Figure 3).

\section{Discussion}

Refugees with PTSD symptoms or other mental health problems may be less likely to engage in treatment approaches based on individual as a change agent, including cognitive behavioral therapy, if they strongly believe they were destined to have these problems. Thus, metaphysical beliefs as etiology for mental health problems, which may reflect the influence of specific religious or spiritual teachings, might be considered while designing mental health promotion and early intervention programs for these communities [16].

Several selected articles dealt with PTSD in refugees; therefore, in order to make reading more comprehensible, Discussion was organized in topics regarding different subjects.

\section{Prevalence}

Alpak et al., [19] examined prevalence of PTSD and explored relationship with various socioeconomic variables among Syrian refugees who sought asylum in Turkey and was detected that majority of participants were female and mean age was 37 years. In contrast, Nakash et al., [21] found that majority of refugees were Eritrean men who had up to 12 years of formal education and were unemployed.

Tay et al., [23] interviewed 230 adults, 107 participants from West Papua, Papua New Guinea, half of participants were in two settlements, 51\% were married and remnant were single, separated or widowed. Half of participants were unemployed. Employees worked in a governmental division, international organizations or in subsistence agriculture or fishing. Slewa-Younan et al., [15] conducted interviews with a total of 225 Iraqis and 150 Afghans. The Afghan group was significantly younger, experienced a longer time displacement and was in Australia for a longer time than the Iraqi group. Unlike the studies cited above, there were no differences in gender, arrival status or marital status between the two groups.

These divergences may be related to group origin or destination place, as well as to socio-cultural issues of different groups interviewed.

\section{Related Traumas}

Slewa-Younan et al., [15] have drawn attention to the growing consensus that factors such as expo- 
sure to intense or prolonged trauma, particularly at a younger age, as well as female gender, are likely to be risk factors for PTSD development. Hecker et al. [20] study was congruent with the notion that, in the context of war and conflict, a cycle of violence persists, relating exposure to organized, community and family violence, to aggressive behavior. Their findings indicate the differential relationship between distinct subtypes of aggression and severity of PTSD symptoms.

McGregor et al., [14] show a significant moderate negative correlation between family, separations and PTSD symptomatology; all other demographic variables were not significant. In addition, findings from the Alpak et al., [19] suggest that PTSD among Syrian refugees in Turkey can be a major mental health problem in refugee camps, especially among refugees who have been exposed to 2 or more traumatic events and had a personal or family history of psychiatric disorder.

Park et al., [22] observed that the 5 most frequently mentioned types of trauma were: witnessing public executions (69.8\%), witnessing a family member or friend's death for starvation (56.8\%), starving (48.2\%), witnessing strong physical violence $(46.2 \%)$, and remotely escaping after desertion (32.2\%). Accordingly, 31.3\% of those interviewed by Feyera et al., [18] have already experienced 8 or more trauma events and more than half (57.4\%) of interviewees already experienced a combat situation. About $45.1 \%$ witnessed murder of family members or friends and 53\% of those interviewed reported witnessing the murder of family members. The majority of refugees interviewed by Tay et al., [23] also reported exposure to at least one traumatic event, including being forced to live in precarious conditions during conflict and having the house intentionally destroyed during the conflict, in addition to the same events cited by Feyera et al., [18]

\section{Main symptoms}

Tay et al., [23] state that the most widely reported symptoms were intrusive thoughts (40.8\%), psychological (31.7\%) and physiological reactions (24.7\%), flashbacks (24.7\%), distressing dreams (23.4\%); internal avoidance (avoiding thoughts) (35.2\%) and external evasion (34.3\%) (avoiding places, people and activities). Other reported symptoms include insomnia (7.8\%), post-traumatic amnesia (7.8\%), affective deregulation (8.3\%), decreased interest $(9.1 \%)$ and hypervigilance (10.8\%). Moreover, Nakash et al., [21] highlight, from interviewing 225 participants, that $39.1 \%$ had severe psychological distress, $18.7 \%$ presented moderate suffering and $37.8 \%$ had low to mild discomfort.

Nygaard et al., [17] show variable psychological symptoms from their sample, differently fom other studies included in the present review. Visual hallucinations were described in 22 of 74 of the patients' psychiatric records. These hallucinations involved family members, for example. Feyera et al., [18] found that women were twice as likely as men to exhibit depression sypmptoms and the likelihood of having depression symptoms, especially divorced ones. In Nakash et al., [21] study, there was a significant positive correlation between anxiety, depression and total exposure to traumatic events.

\section{Conclusion}

Refugee status is classically associated with war situation, conflict, family loss and human rights' compromise. Seeking refuge itself can sometimes represent being subjected to a suffering and trauma environment, partly due rupture from several cultural aspects that are significant for building a sense of belonging sense, as well as for the refugee's identity.

In this conflict perspective, PTSD is a major mental health problem in populations such as refugees. Being exposed to intense and prolonged traumas are probable risk factors for developing PTSD. Ex- 
posure to organized, community and family violence is related to aggressive behaviors and, thus, to the severity with which symptoms of post-traumatic stress are manifested.

In addition, there are gender differences in PTSD prevalence; however, these differences vary depending on the studied sample, which represent not only groups originating from different locations, but also different destinations and socio-cultural contexts. Younger groups of refugees more frequently manifested PTSD symptoms.

The most frequent traumas are witnessing public executions, witnessing family or friends' deaths, starving, witnessing severe physical violence, and remotely escaping after desertion. Clinical significance of these traumas is suggested when they are related to symptoms in refugees, such as intrusive thoughts, visual hallucinations, flashbacks, distressing dreams, internal evasion, external evasion, and other psychological and physiological reactions. In addition to PTSD, depressive symptoms were commonly associated with trauma and the acculturation process in refugees, so women, especially divorced women, who are more likely to show symptoms when compared to men.

Although the clinical importance of migrationrelated traumas is well documented in current scientific literature, the way by which this relates to PTSD, as well as other impacts in heatlh should be better explored. In addition, physiological mechanisms that explain PTSD genesis, especially in refugee populations, may differ from conventional populations and have not yet been clarified by the available results.

Studies suggest the importance of improving existing health care models in countries receiving refugees, in order to include aspects hitherto studied, considering difficulties for refugees to engage certain therapeutic approaches and clinical aspects that are relevant to mental health and to process of health-disease in the care for this group.

\section{Highlights}

Exposure to traumatic events such as public executions and other extreme acts of violence, murder of family members, family and friends' death due to starvation, homelessness, are closely related to PTSD prevalence in refugees.

Acculturation and family's prolonged estrangement are predictors of depressive symptoms in refugees and both exposure to a new culture and adaptation to new laws and norms of welcoming countries act as stressors and aggravators of depressive symptoms.

\section{Conflict of interest}

The authors declare that they have no competing interests.

\section{References}

1. Corrêa Mas, Nepomuceno Rb, Mattos Whc, Miranda C. Migração Por Sobrevivência: Soluções Brasileiras. Remhu - Rev. Interdiscip. Mobil. Hum., 2015, 23(44):221-236.

2. Abbott A. The Troubled Minds Of Migrants. Nature, 2016, 538: 159-161.

3. Un High Commissioner For Refugees. Desperate Journeys: Refugees And Migrants Entering And Crossing Europe Via The Mediterranean And Western Balkans Routes. UNHCR Report, 2017. Disponível Em: https://Reliefweb.Int/Report/World/ Desperate-Journeys-Refugees-And-Migrants-Entering-AndCrossing-Europe-Mediterranean-And

4. Almeida A, Ahlert M. A Inclusão Social Das Pessoas Na Condição De Refugiado No Brasil à Luz Dos Direitos Humanos. Barbaról, Edição Especial, 2016, 47: 09-21.

5. Ubel Rrg. A MudançA Da Política Externa Brasileira Para Imigrantes E Refugiados: O Caso Da Migração Haitiana No Início Do Século XXI. Barbarói, Edição Especial, 2016, 47: 22-43.

6. Unacr/Acnur. Refugiado Ou Migrante? O Acnur Incentiva A Usar O Termo Correto. ACNUR, 2015. Disponível Em: http:// Www.Acnur.Org/Portugues/Noticias/Noticia/Refugiado-OuMigrante-O-Acnur-Incentiva-A-Usar-O-Termo-Correto/

7. Gediel Jap, Godoy Gg. Refúgio E Hospitalidade. Curitiba: Kairós, 2016.

8. Martins-Borges L. Migração Involuntária Como Fator De Risco à SaúDe Mental. Rev. Inter. Mob. Hum, 2013, 40: 151-162.

9. Indursky A, Oliveira Lep. Sobre A Melancolização Do Exílio. Rev. Latinoam. Psicopat. Fund., 2016, 19(2): 242-258. 
10. Gabriel P, Kaczorowski J, Berry N. Recruitment Of Refugees For Health Research: A Qualitative Study To Add Refugees' Perspectives. Int. J. Environ. Res. Public Health, 2017, 14: 125135.

11. Unterhitzenberger J, Eberle-Sejari R, Rassenhofer $M$, Sukale $T$, Rosner R, Goldbeck L. Trauma-Focused Cognitive Behavioral Therapy With Unaccompanied Refugee Minors: A Case Series. Bmc Psychiatry, 2015, 15: 260.

12. Haagen Jfg, Heide Fjj, Mooren Tm, Knipscheer Jw, Kleber Rj. Predicting Post-Traumatic Stress Disorder Treatment Response In Refugees: Multilevel Analysis. British Journal Of Clinical Psychology, 2017, 56: 69-83.

13. Llosa MV. Niño Muerto En La Playa. [Opinión.] El PaíS. 20 Set. 2015. Access: 20/10/17. Available From: http://Elpais.Com/ Elpais/2015/09/18/Opinion/1442579286 144627. Html.

14. Mcgregor Ls, Melvin Ga, Newman Lk. Familial Separations, Coping Styles, And Ptsd Symptomatology In Resettled Refugee Youth. The Journal Of Nervous And Mental Disease, 2015, 203(6): 431-438

15. Slewa-Younan S, Guarajardo Gu, Yaser A, Mond J, Smith M, Milosevic D, Smith C, Lujic S, Jorm F. Causes Of And Risk Factors For Posttraumatic Stress Disorder: The Beliefs Of Iraqi And Afghan Refugees Resettled In Australia. Int J Ment Health Syst, 2017, 11: 4-15.

16. Slewa-Younan S, Mond J, Bussion E, Mohammad Y, Guajardo Mgu, Smith M, Milosevic D, Lujic S, Jorm Af. Mental Health Literacy Of Resettled Iraqi Refugees In Australia: Knowledge About Posttraumatic Stress Disorder And Beliefs About Helpfulness Of Interventions. Bmc Psychiatry, 2014, 14: 320328.

17. Nygaard M, Sonne C, Carlsson J. Secondary Psychotic Features In Refugees Diagnosed With Post-Traumatic Stress Disorder: A Retrospective Cohort Study. Bmc Psychiatry, 2017, 17: 5-16.

18. Feyera F, Mihretie G, Bedaso A, Gedle D, Kumera G. Prevalence Of Depression And Associated Factors Among Somali Refugee At Melkadida Camp, Southeast Ethiopia: A Cross-Sectional Study. Bmc Psychiatry, 2015, 15: 171-178.

19. Alpak G, Unal A, Bulbul F, Sagaltici E, Bez Y, Altindag A, Dalkilic A, Savas Ad. Post-Traumatic Stress Disorder Among Syrian Refugees In Turkey: A Cross-Sectional Study. Int J Psychiatry Clin Pract, 2014, Early Online: 1-6.
20. Hecker $T$, Fetz $S$, Ainamani $H$, Elbert $T$. The Cycle Of Violence: Associations Between Exposure To Violence, Trauma-Related Symptoms And Aggression-Findings From Congolese Refugees In Uganda. Journal Of Traumatic Stress, 2015, 28: 448-455.

21. Nakash O, Nagar M, Shoshani A, Lurie I. The Association Between Acculturation Patterns And Mental Health Symptoms Among Eritrean And Sudanese Asylum Seekers In Israel. Cultural Diversity And Ethnic Minority, 2015, 21(3): 468-476.

22. Park J, Jun Jy, Lee $Y$ I, Kima S, Lee S, Yoo Sy, Kim Sj. The Association Between Alexithymia And Posttraumatic Stress Symptoms Following Multiple Exposures To Traumatic Events In North Korean Refugees. Journal Of Psychosomatic Research, 2015, 78: 77-81.

23. Tay Ak, Rees S, Chan J, Kareth M, Silove D. Examining The Broader Psychosocial Effects Of Mass Conflict On Ptsd Symptoms And Functional Impairment Amongst West Papuan Refugees Resettled In Papua New Guinea (Png). Social Science \& Medicine, 2015, 132: 70-78.
Publish in International Archives of Medicine

International Archives of Medicine is an open access journal publishing articles encompassing all aspects of medical science and clinical practice. IAM is considered a megajournal with independent sections on all areas of medicine. IAM is a really international journal with authors and board members from all around the world. The journal is widely indexed and classified Q2 in category Medicine. 